\title{
Bacterial Translocation in Clinical Intestinal Transplantation
}

\author{
L. Cicalese, P. Sileri, M. Green, K. Abu-Elmagd, J.J. Fung, T.E. Starzl, and J. Reyes \\ Thomas E. Starzl Transplantation Institute, University of Pittsburgh Medical Center, Pittsburgh, \\ Pennsylvania, USA
}

Infectious complications and sepsis are associated with high morbidity and mortality in human and experimental small bowel transplantation. ${ }^{1}$ Enteric microflora is thought to play an important role in the genesis of these infections. The transit of viable bacteria through the intestinal epithelium into the lamina propria, and consequently to the mesenteric lymph nodes, peritoneal cavity, and other previously sterile tissues, is called bacterial translocation (BT). Translocation of microorganisms from the GI tract has been demonstrated in animal and human studies. ${ }^{2,3}$ Although BT has been suggested to be the mechanism responsible for the high rate of infections occurring after clinical small bowel transplantation (SBTx), data are not available. Bacterial overgrowth, alteration of the mucosal barrier function, consequence of preservation injury or acute rejection (AR), and the use of potent immunosuppression have all been considered responsible for BT in SBTx. ${ }^{4-6}$ The aim of this study was to evaluate the correlation of BT with these events.

\section{MATERIALS AND METHODS}

Fifty pediatric SBTx recipients (26 boys and 24 girls) with a follow-up ranging from 20 days to 6 years (mean \pm SD: $30 \pm 10$ months) under tacrolimus and prednisone immunosuppression were analyzed. Among these, 14 received isolated small bowel (SB), 28 liver and SB (LSB), and 8 multivisceral (MV) allografts. A colon graft was included in 16 patients (4 in SB, 8 in SBL, 4 in MV). Blood, stool, liver biopsies, and peritoneal fluid were collected when infection was clinically suspected or as part of follow-up, and cultures were performed using standard microbiological techniques. Approximately 4000 cultures were evaluated in the study. BT episodes were considered when microorganisms were found simultaneously in blood or liver biopsy and feces, whereas positive central line blood samples without peripheral confirmation were discarded. Acute rejection (AR) episodes were considered only if confirmed histologically and counted as one if within a 3-week duration. The Fisher Exact test was used for statistical analysis.

\section{RESULTS AND DISCUSSION}

BT (average of 2.0 episodes/patient) was evident in $44 \%$ of patients (36\% in SB, $50.0 \%$ in SBL, $37.5 \%$ in MV group) most frequently caused by enterococci staphylococci, enterobacter, and klebsiella. The presence of the colon graft was associated with a higher bacterial count in the stool ( $100 \%$ cultures $>1 \times 10^{6} \mathrm{CFU}$ ) and BT ( $75 \%$ of patients) compared to the patients without colon $\left(84.6 \%\right.$ cultures $>1 \times 10^{6} \mathrm{CFU}$; BT $33.3 \%$ of patients). Furthermore, the type of transplant profoundly affected the rate of BT (group with vs without colon: $\mathrm{SB}=40 \%$ vs $25 \%$; $\mathrm{LSB}=100 \%$ vs $30 \%$; $\mathrm{MV}=25 \%$ vs $50 \%$ ). AR took place in $36 \%$ of all BT episodes. From a total of 167 episodes of AR only $9.6 \%$ were followed by BT, while an additional $5.2 \%$ were followed by bacteriemia or positive tissue

Address reprint requests to Dr Luca Cicalese, Clinical Science Building, Room 402, 840 South Wood Street (MC 958), Chicago, IL 60612. 
culture without fecal confirmation of the bacteria at examination. However, the rate of BT was observed in a significantly higher number of patients with cold ischemia time (CIT) $>9$ hours when compared to patients with CIT $<9$ hours $(76 \%$ vs $20.8 \%, P=.002)$.

\section{CONCLUSIONS}

This study shows that: (1) even though, during AR, mucosal damage occurs and immunosuppression is substantially increased, this is not accompanied by an increased BT rate; (2) the presence of colon graft caused an increment increase in fecal bacterial counts and BT; (3) the duration of CIT strongly influences the rate of BT after SBTx in children. Taken together these data provide a new view of the mechanisms associated with infections after SBTx.

\section{References}

1. Abu Elmagd K, Todo S, Tzakis A, et al. Transplant Proc 1994;26:1684. [PubMed: 8030087]

2. Sedman PC, MacFie J, Sagar P. Gastroenterology 1994;107:643. [PubMed: 8076751]

3. Cicalese L, Aitouche A, Ploskina BS, et al. Transplant Proc 1999;31:1922. [PubMed: 10391799]

4. Fryer JP, Kim S, Wells CL, et al. Arch Surg 1996;131:77. [PubMed: 8546583]

5. Kusne S, Manez R, Bonet H, et al. Transplant Proc 1994;26:1682. [PubMed: 7518153]

6. Biffi R, Privitera G, Matinato C, et al. Transplant Proc 1996;28:2662. [PubMed: 8908000] 